\title{
Design and fabrication of chemically robust three-dimensional microfluidic valves $\dagger$
}

\author{
George Maltezos, ${ }^{a}$ Erika Garcia, ${ }^{b}$ Grady Hanrahan, ${ }^{* b}$ Frank A. Gomez, ${ }^{b}$ Saurabh Vyawhare, ${ }^{a}$ \\ R. Michael van Dam, $\ddagger^{a}$ Yan Chen ${ }^{a}$ and Axel Scherer*a
}

Received 3rd April 2007, Accepted 18th June 2007

First published as an Advance Article on the web 9th July 2007

DOI: $10.1039 / \mathrm{b} 705031 \mathrm{c}$

A current problem in microfluidics is that poly(dimethylsiloxane) (PDMS), used to fabricate many microfluidic devices, is not compatible with most organic solvents. Fluorinated compounds are more chemically robust than PDMS but, historically, it has been nearly impossible to construct valves out of them by multilayer soft lithography (MSL) due to the difficulty of bonding layers made of "non-stick" fluoropolymers necessary to create traditional microfluidic valves. With our new three-dimensional (3D) valve design we can fabricate microfluidic devices from fluorinated compounds in a single monolithic layer that is resistant to most organic solvents with minimal swelling. This paper describes the design and development of 3D microfluidic valves by molding of a perfluoropolyether, termed Sifel, onto printed wax molds. The fabrication of Sifel-based microfluidic devices using this technique has great potential in chemical synthesis and analysis.

\section{Introduction}

During the past decade soft polymers, such as poly(dimethylsiloxane) (PDMS), have emerged as the material of choice for microfluidic devices and are rapidly emerging as ubiquitous platforms for numerous applications. ${ }^{1-17}$ PDMS offers the advantages of being inexpensive and simple to fabricate using rapid prototyping. ${ }^{3-5}$ It exhibits elastomeric properties with a surface energy of $\sim 20 \mathrm{erg} \mathrm{cm}^{-2}$ and low Young's modulus value of $\sim 750 \mathrm{kPa}$, thus allowing the material to conform and easily seal to other surfaces, both reversibly and irreversibly. ${ }^{7}$

Despite the advantages of PDMS in microfluidic applications, one of the most prominent drawbacks with its use is its incompatibility with many organic solvents including acyclic and cyclic hydrocarbons (e.g. pentanes, hexanes, cyclohexane), aromatic hydrocarbons (e.g. xylenes, toluene, benzene), halogenated compounds (e.g. chloroform, trichloroethylene), ethers (e.g. diethyl ether, dimethoxyethane, tetrahydrofuran), and amines (e.g. diisopropylamine, dipropylamine, triethylamine). ${ }^{9}$ These solvents can cause swelling in the material, leading to changes in the cross-sectional area of microchannels and, therefore, changes in the rate of flow. Swelling can also alter surface properties and cause the device to de-seal. As a result, applications involving organic solvents require the use of other device materials.

${ }^{a}$ Electrical Engineering and Applied Physics, California Institute of Technology, Pasadena, CA, 91125, USA. E-mail: etcher@caltech.edu.; Fax: +1 626577 8442; Tel: +1 6263954578

${ }^{b}$ Department of Chemistry and Biochemistry, California State

University Los Angeles, Los Angeles, CA, 90032, USA.

E-mail: ghanrah@calstatela.edu.; Fax: +1 323-343-6490;

Tel: +1 323-343-2365

$\uparrow$ Electronic supplementary information (ESI) available: A graph of fluid flow versus actuating pressure. See DOI: 10.1039/b705031c

* Present address: Department of Molecular and Medical Pharmacology, University of California, Los Angeles, Los Angeles, CA 90095, USA
Herein, we report a novel solvent-resistant microfluidic device based on a perfluoropolyether (termed Sifel) and threedimensional (3D) microvalves from printed wax molds. Sifel consists of a perfluoropolyether backbone (Fig. 1) which is particularly stable due to the strength of the carbon-fluorine bond and steric hindrance arising from the strong forces between hydrogen and fluorine atoms. Sifel contains no solvents, withstands temperatures up to $200{ }^{\circ} \mathrm{C}$ and is elastic to $-50{ }^{\circ} \mathrm{C}$. Hardness after cure (Shore A) was measured at 34 by DMA for a range from $-40{ }^{\circ} \mathrm{C}$ to $150{ }^{\circ} \mathrm{C}$. Other physical parameters of interest include low moisture permeability $\left(5 \mathrm{~g} \mathrm{~m}^{-2}\right.$ over $\left.24 \mathrm{~h}\right)$, volume resistivity $\left(1 \times 10^{15} \Omega \mathrm{cm}\right)$, viscosity $\left(2.7 \mathrm{~Pa} \mathrm{~s}\right.$ at $\left.23{ }^{\circ} \mathrm{C}\right)$, conductivity $\left(0.11 \mathrm{~W} \mathrm{~m}^{-1} \mathrm{~K}^{-1}\right)$, tensile strength $(0.9 \mathrm{MPa})$ and elongation $(110 \%)$. In addition, Sifel is very pure, with ionic species (e.g. $\mathrm{Na}^{+}, \mathrm{K}^{+}$, $\mathrm{NH}_{4}{ }^{+}, \mathrm{F}^{-}, \mathrm{Cl}^{-}$) below 1 ppm.

Similar studies have used photocurable perfluoropolyethers to fabricate two-layer (flow and control) microfluidic devices. ${ }^{18}$ The method of these studies involved joining two partially cured perfluoropolymer layers together in a very difficult and low yield fabrication step. However, the wax mold design ${ }^{19}$ presented herein eliminates the intricacies involved with adhering partially cured fluoropolyether layers by eliminating the need for a bonding step altogether. By molding a monolithic device from a single mold containing both flow and control channels, this technique enables the use of

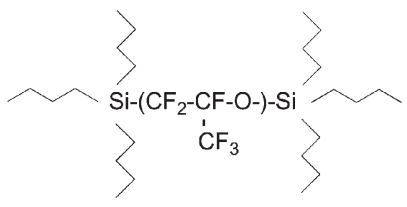

Fig. 1 The perfluoropolyether backbone with terminal silicon cross linking groups of Sifel. 
elastomers that do not satisfy the adhesion requirements of multilayer fabrication required by the previous studies. After curing by heat, Sifel becomes a high-performance elastomer with extraordinary levels of resistance to chemicals, oil, and heat ${ }^{20}$ thus opening up a vast array of potential microfluidic applications in areas otherwise limited.

In such three-dimensional fluidic chips, the smallest flow pressure line that can be defined by the lateral and vertical resolution of the wax printer described in this study is $115 \mu \mathrm{m}$ wide by $12.5 \mu \mathrm{m}$ high (although some difficult geometries require more mold material strength and must be made larger). These dimensions match well with geometries suitable for the definition of useful microfluidic applications. It is well known that in geometries much below $10 \mu \mathrm{m}$ the Reynold's number is very low and the differential fluid flow velocity in the center of the channel versus at the channel wall can be significant. ${ }^{19,21}$ These effects limit the usefulness of fluidic systems with dimensions much below the channels and valves that we describe here. Rapid prototyping of microfluidic devices with a solid-object printer has also been reported by the Backhouse ${ }^{21}$ and Whitesides ${ }^{22}$ groups, but neither group demonstrated devices with integrated microvalves without bonding, because the printers employed were only capable of generating essentially two-dimensional patterns.

\section{Methods and materials}

The wax molds were designed in three-dimensions using a SolidWorks CAD software (SolidWorks Corporation, MA, USA) and the file was printed directly onto a glass substrate by means of a commercial wax printing system (Solidscape T66, NH, USA). Printing was carried out with two waxes (Proquest Solutions, Inc., CA, USA): the building wax (blue) which formed the structure of the desired microchannels and the supporting wax (red) which acted as a sacrificial material and supported suspended structures during fabrication. The supporting wax was removed by placing the molds in a petri dish containing VS-O precision cleaner (Petroferm, Inc., FL, USA) for approximately $1 \mathrm{~h}$ at $65^{\circ} \mathrm{C}$. Next, the wax molds were dried at $40{ }^{\circ} \mathrm{C}$ for approximately $3 \mathrm{~h}$. Once the molds were dry, 25 gauge pins were heated and inserted into each valve mold, with the wax melting enough to accept and seal to the heated metal pin, and then resolidifying. To minimize the amount of Sifel required to form the valve, PDMS (Sylgard ${ }^{\circledR} 184$, Dow Corning, MI, USA) blocks were created by pouring a liquid PDMS pre-polymer (mixture of $10: 1$ base polymer : curing agent) onto a petri dish and allowing the mixture to cure at $70{ }^{\circ} \mathrm{C}$ for 1 hour. Cylindrical holes were punched through the PDMS with the blocks then placed around each wax mold providing a cavity to contain the Sifel. Next, Sifel (Shin-Etsu Silicones, Inc., SC, USA) was poured over the models and allowed to cure at $60{ }^{\circ} \mathrm{C}$ for approximately $24 \mathrm{~h}$. Finally the building wax was melted away at up to $150{ }^{\circ} \mathrm{C}$ to provide the completed structure (Fig. 2). The glass mold substrate serves also as the device substrate, as Sifel forms a permanent bond to it during curing.

The degree of swelling was measured by adopting the method of Lee et al. ${ }^{9}$ Solid pieces of Sifel were placed in chosen solvents for $24 \mathrm{~h}$ with subsequent measurements in dimension (length) taken. The Sifel blocks (three replicates for each solvent) were cut in the shape of rectangles $(4 \mathrm{~mm} l \times$ $2 \mathrm{~mm} w \times 2 \mathrm{~mm} h$ ) and immersed in each solvent for $24 \mathrm{~h}$ at $25{ }^{\circ} \mathrm{C}$. After $24 \mathrm{~h}$, the pieces were measured while still submersed with digital callipers $( \pm 0.02 \mathrm{~mm}$ accuracy, ZZW Precision Tool Supply, China) with the mean value used for calculation purposes. The degree of swelling was expressed by the swelling ratio $(S)$ :

$$
S=\frac{D}{D_{0}}
$$

where $D$ is the length of the Sifel exposed to the solvent and $D_{0}$ is the length of the dry Sifel.

\section{Results and discussion}

We report on the successful design and fabrication of $3 \mathrm{D}$ microfluidic valves by molding of a novel perfluoropolyether onto printed wax molds. The completed structure (Fig. 2c) featured a suspended fluid flow tube surrounded by a doughnut shaped pressure chamber. In this design, pressure was applied around the entire fluid channel, deflecting a thin Sifel membrane inward. This deflection closed the suspended channel and stopped fluid flow. Valve actuation was controlled by varying the pressure applied to the control channel. As a result, these valves could be used for microfluidic metering and flow control.
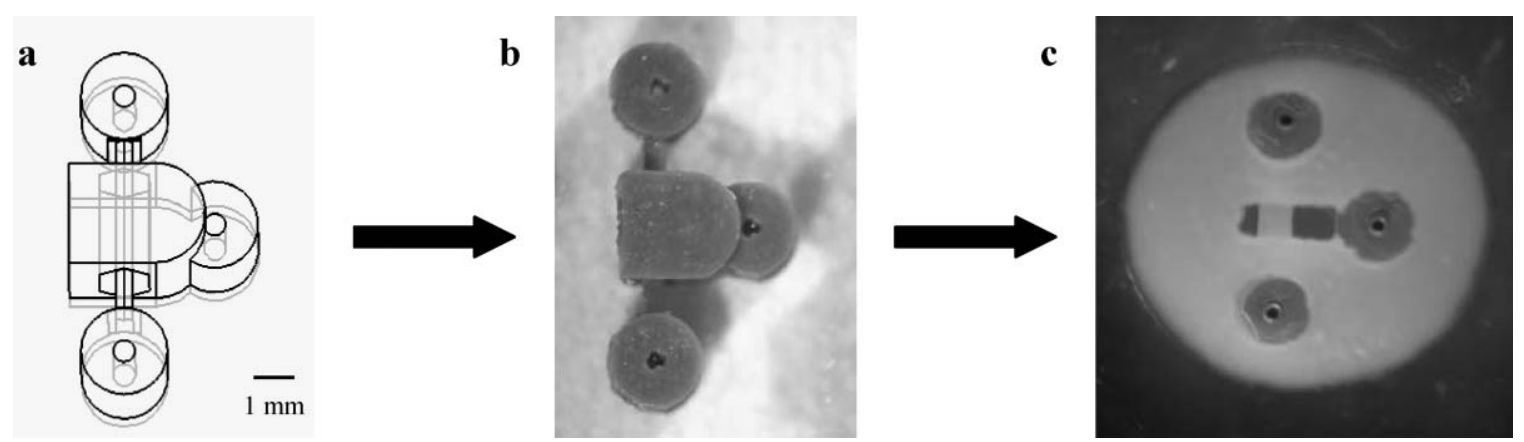

Fig. 2 Scheme for fabricating devices in Sifel using a wax printer. (a) A Solidworks file is generated that defines the system in 3D. (b) The object is then printed onto a glass substrate using a commercial wax printing system. (c) Once the object is printed, Sifel is poured over the mold and cured at $60{ }^{\circ} \mathrm{C}$ for $24 \mathrm{~h}$. Once cured, the building wax is removed to reveal the completed structure. 
Table 1 Comparison of Sifel and PDMS swelling ratios in representative organic solvents

\begin{tabular}{lll}
\hline Solvent & Swelling ratio Sifel $^{a}$ & Swelling ratio PDMS $^{b}$ \\
\hline Diisopropylamine & 1.07 & 2.13 \\
Hexane & 1.03 & 1.35 \\
Triethylamine & 1.07 & 1.58 \\
Trichloroethylene & 1.05 & 1.34 \\
Xylenes & 1.02 & 1.41 \\
Toluene & 1.03 & 1.31 \\
Chloroform & 1.07 & 1.39 \\
Tetrahydrofuran & 1.08 & 1.38 \\
Methylene chloride & 1.04 & 1.22 \\
${ }^{a}$ Mean value reported $(n=3)^{b}$ As reported by Lee et al. ${ }^{9}$ \\
\hline
\end{tabular}

Introduction of fluid into this device was accomplished through steel pins inserted into holes formed through the material. These holes were formed by 25 gauge steel pins previously melted into the wax mold. The pins were taken out after the Sifel was cured and 21 gauge tubes then used to form a tight seal around the input pins, readily accepting pressures up to 21 psi without leakage. Above this pressure the seal was likely to leak air, as tested by immersion in water and inspection for bubbles escaping from the pressurized seal. This hole-molding method solved one difficult problem with many fluoropolymers - that they cannot be hole-punched without cracking and leaks.

Four samples of polymer: Sifel 610, Sifel 611, Sifel X-716030, and Sifel X-71-6054, were cured to milky white elastomeric materials and tested for adhesion to glass surfaces. Since fluid flow was pressure-driven, it was necessary to form an irreversible seal between the glass substrate that the mold is printed on and Sifel. Both Sifel X-71-6054 and Sifel X-71-6030 were less viscous than the other two materials but easily peeled off from the glass. Both Sifel 610 and Sifel 611 adhered very strongly to glass surfaces upon curing. However, Sifel 611 was extremely viscous which made it difficult to completely de-gas and remove all air bubbles. Sifel 610 adhered well to the glass and was more fluid than the Sifel 611, which made it ideal for pouring over the wax molds for fabrication of the microfluidic devices.

Examination of swelling ratios of Sifel by nine representative organic solvents was performed and compared to PDMS values reported by Lee et al. ${ }^{9}$ (Table 1). Classification was based upon their solubility effect on Sifel using the following relationship: ${ }^{9}$ low solubility $=1.00<S<1.10$; moderate solubility $=1.10<S<1.22$; high solubility $=1.28<S<1.58$; extreme solubility $=1.58<S<2.13$. As shown, low solubility was observed for all organic solvents tested, in contrast with the significantly higher values reported for PDMS. ${ }^{9}$

A study was performed to assess the Sifel valve closing pressure (pressure in air chamber to deflect the valve for closing) in relation to fluid flow rate through the valve. Here, a fluid flow pressure of 2 psi was used as an example application. The valve closed at $18 \mathrm{psi}, 16 \mathrm{psi}$ above the flow pressure. A graph of fluid flow versus actuating pressure is shown in the Electronic Supplementary Information section $\dagger$. Each point on the graph is a mean of three runs $\pm 3 \sigma$ (error bars).

\section{Concluding remarks}

By replacing PDMS with Sifel, this novel wax printing method allows for the fabrication of topologically complex 3D microfluidic structures and offers many advantages over multilayer soft lithography, including ease of fabrication, rapid response time and high levels of integration. The major advantage of developing devices from 3D molding is that it enables the use of a myriad of elastomers, like Sifel, that are more solventresistant than PDMS. As a result, the fabrication of more complex structures can be achieved with the potential to expand the field of highly integrated microfluidics to many new applications in chemical synthesis and analysis.

\section{Acknowledgements}

The authors gratefully acknowledge financial support for this research by grants from the National Science Foundation (CHE-0515363 and DMR-0351848), and the National Institutes of Health (1R15AI65468-01). GH also acknowledges partial support from the National Institute of Health (1P20 MD001824-01). We are also grateful to Mr Claude C. McClure of Shin-Etsu Silicones, Inc. for providing the Sifel and product details.

\section{References}

1 G. M. Whitesides, Nature, 2006, 442, 368-373.

2 J. P. Urbanski, W. Thies, C. Rhodes, S. Amarasinghe and T. Thorsen, Lab Chip, 2006, 6, 96-104.

3 G. M. Whitesides and A. D. Stroock, Phys. Today, 2001, 54, 42-48.

4 S. Sia and G. M. Whitesides, Electrophoresis, 2003, 24, 3563-3576.

5 D. Weibel, M. Kruithof, S. Potenta, S. Sia, A. Lee and G. M. Whitesides, Anal. Chem., 2005, 77, 4726-4733.

6 J. de Jong, R. G. H. Lammertink and M. Wessling, Lab Chip, 2006, 6, 1125-1139.

7 J. McDonald and G. M. Whitesides, Acc. Chem. Res., 2002, 35, 491-499.

8 J. S. Go and S. Shoji, Sens. Actuators, A, 2004, 114, 438-444.

9 J. Lee, C. Park and G. M. Whitesides, Anal. Chem., 2003, 75 , 6544-6554.

10 O. Hofmann, P. Niedermann and A. Manz, Lab Chip, 2001, 1, 108-114.

11 P. G. Gross, E. P. Kartalov, A. Scherer and L. P. Weiner, J. Neurol. Sci., 2007, 252, 135-143.

12 M. W. Toepke and D. J. Beebe, Lab Chip, 2006, 6, 1484-1486.

13 C.-W. Li, J. Yang, C. H. Tzang, J. Zhao and M. Yang, Sens. Actuators, A, 2006, 126, 463-468.

14 J. Y. Kim, J. Y. Baek, K. A. Lee and S. H. Lee, Sens. Actuators, A, 2005, 119, 593-599.

15 L. Marle and G. M. Greenway, TrAC, Trends. Anal. Chem., 2005, 24, 795-801.

16 G. V. Kaigala, S. Ho, R. Penterman and C. J. Backhouse, Lab Chip, 2007, 7, 384-387.

17 J. Rolland, R. van Dam, D. Schorzman, S. Quake and J. DeSimone, J. Am. Chem. Soc., 2004, 126, 2322-2323.

18 G. Maltezos, M. Johnston, D. G. Maltezos and A. Scherer, Sens. Actuators, A, 2007, 135, 620-624.

19 L. Waksman, H. Kishita, S. Sato and Y. Tarumi, SAE Trans., 2001, 110, 849-856.

20 T. Mautner, Biosens. Bioelectron., 2004, 19, 1409-1419.

21 G. Kaigala, S. Ho, R. Penterman and C. J. Backhouse, Lab Chip, 2007, 7, 384-387.

22 J. C. McDonald, M. L. Chabinyc, S. J. Metallo, J. R. Anderson, A. D. Stroock and G. M. Whitesides, Anal. Chem., 2002, 74, $1537-1545$ 